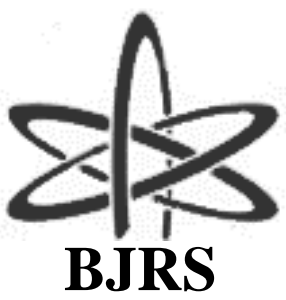

BRAZILIAN JOURNAL

$\mathrm{OF}$

RADIATION SCIENCES

03-1A (2015) 01-12

\title{
Estimation of dose distribution in occupationally exposed individuals to $\mathrm{FDG}-{ }^{18} \mathrm{~F}$
}

\author{
I. V. B. Lacerda ; M. O. M. Cabral ${ }^{\mathrm{a}}$; J. W. Vieira, ${ }^{\mathrm{a}, \mathrm{b}, \mathrm{c}}$ M. L. Oliveira,d, F. R. A. \\ Lima $^{\mathrm{a}, \mathrm{d}}$ \\ ${ }^{a}$ Departamento de Energia Nuclear (DEN-UFPE), 50740-540, Recife-PE, Brasil \\ ilacerda.bolsista@cnen.gov.br,manuela.omc@gmail.com
}

${ }^{b}$ Instituto Federal de Educação, Ciência e Tecnologia de Pernambuco (IFPE), 50740-540, Recife-PE, Brasil jose.wilson59@uol.com.br

${ }^{c}$ Escola Politécnica de Pernambuco (EPP-UPE), 50720-001, Recife-PE, Brasil

jose.wilson59@uol.com.br

${ }^{d}$ Centro Regional de Ciências Nucleares do Nordeste (CRCN-NE), 50740-540, Recife-PE, Brasil

mercial@cnen.gov.br,falima@cnen.gov.br.com.br

\begin{abstract}
The use of unsealed radiation sources in nuclear medicine can lead to important incorporation of radionuclides, especially for occupationally exposed individuals (OEIs) during production and handling of radiopharmaceuticals. In this study, computer simulation was proposed as an alternative methodology for evaluation of the absorbed dose distribution and for the effective dose value in OEIs. For this purpose, the Exposure Computational Model (ECM) which is named as FSUP (Female Adult Mesh - supine) were used. This ECM is composed of: voxel phantom FASH (Female Adult MeSH) in the supine position, the MC code EGSnrc and an algorythm simulator of general internal source. This algorithm was modified to adapt to specific needs of the positronic emission from FDG-18F. The obtained results are presented as absorbed dose/accumulated activity. To obtain the absorbed dose distribution it was necessary to use accumulative activity data from the in vivo bioassay. The absorbed dose distribution and the
\end{abstract}


value of estimated effective dose in this study did not exceed the limits for occupational exposure. Therefore, the creation of a database with the distribution of accumulated activity is suggested in order to estimate the absorbed dose in radiosensitive organs and the effective dose for OEI in similar environment.

Keywords: EGSnrc, OEI, FDG-18F

\section{INTRODUCTION}

The use of nuclear technology has grown considerably in numerous areas, increasing the production of radioactive sources and the number of occupationally exposed individuals (OEI) subjected to radionuclides. The absorbed dose resulting from the use of ionizing radiation could imply biological effects in workers. Therefore, its accurate estimation is essential for radioprotection of the OEIs.

In nuclear medicine, the use of open radiation sources can lead to significant incorporation of radionuclides, especially during the production and handling of radiopharmaceuticals procedures [1]. The radiopharmaceutical FDG $-{ }^{18} \mathrm{~F}$ is the positron emitter most currently used in PET scans (Positron Emission Tomography). It is routinely produced at Divisão de Produção de Radiofármacos (DIPRA), Centro Regional de Ciências Nucleares do Nordeste (CRCN$N E / C N E N)$, where the methodology for internal monitoring of OEIs was implemented through in vivo bioassay technique [2]. The incorporated activity data resulting from this technique was used to obtain the distribution of absorbed dose.

The in vivo bioassay technique is recognized as a valuable tool in radioprotection as well as in dosimetry [3] and is characterized by the positioning of radiation detectors near to the predefined body regions. This technique allows to identify and locate the radionuclides present in the body at the moment of measurement, and to estimate the absorbed dose by the determination of incorporated activity. 
The absorbed dose is related to the accumulated activity in the source organs. The values of absorbed dose can not be measured directly in an exposed individual and direct measurements with radiation detectors are practically restricted to the body surface [4]. Therefore, exposure computational models (ECM) are used to calculate the dosimetric quantities of interest and to evaluate the effect of the radiation produced in the environment. The ECM is composed of an:

\section{1) Algorithm for radioactive sources:}

To generate the initial state of the particles it is necessary simulate the type of radioactive source of interest. The variables that compose the initial state (which will be implemented by the source algorithm) are: energy and initial particle position (x, y, z) and the initial direction of flight $(\cos \alpha, \cos \beta, \cos \gamma)[5]$.

\section{2) Phantom:}

The phantoms used in computational dosimetry are predominantly constructed from stacks of magnetic resonance imaging (MRI) or of computed tomography (CT) (obtained from real patients scanning) or using specific software for 3D modeling. These phantoms possess the necessary anatomical realism to simulate human organs and tissues and to obtain satisfactory dosimetric results.

\section{3) Monte Carlo code:}

For use in numerical dosimetry the phantom requires the coupling to the MC code. The MC methods can be defined as statistical methods of simulation, where a statistical simulation is defined as any technique that utilizes random numbers sequences somewhere in the approached problem [6].

This paper shows an alternative methodology used to obtain the dosimetric evaluation by experimental measurements from in vivo internal monitoring of OEIs data and computational simulations using an ECM is presented. 


\section{MATERIALS AND METHODS}

\subsection{Experimental Measurements Using The In Vivo Bioassay Method}

The experimental data presented in this paper were obtained by individual monitoring for internal exposure, according to the methodology implemented at DIPRA/CRCN-NE/CNEN. The scintillator detector used in the in vivo bioassay technique was the 3" x 3" NaI(TI), model 802, manufactured by Canberra, connected to a compact module, Unispec, and controlled by the data acquisition system, Genie 2000 software.

For calibration, a simulation of a contaminated individual was performed using a brain geometry (artificial skull resin), containing standard solution of Sodium-22, placed $3 \mathrm{~cm}$ from the detector, as shown in Figure 1. This geometry was chosen due to the high absorption of FDG $-{ }^{18} \mathrm{~F}$ by the brain.

Figure 1: Positioning of the phantom in relation to the detector (indicative arrow)

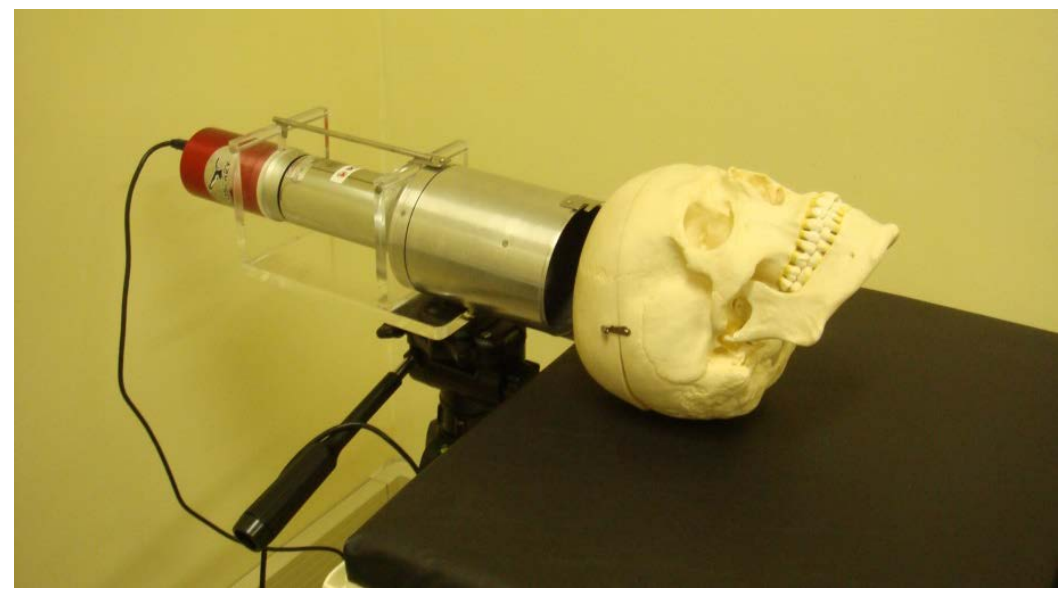

Source: The author

The in vivo measurements were performed on seven volunteers OEIs with duration of 15 minutes each, shortly after synthesis and quality control of the radiopharmaceutical FDG- ${ }^{18} \mathrm{~F}$ procedures. The OEIs were kept in a supine position with the $\mathrm{NaI}(\mathrm{Tl})$ detector in the same geometry utilized to the calibration procedure, as shown in Figure 2. 
Figure 2: OEI positioning in relation to the detector

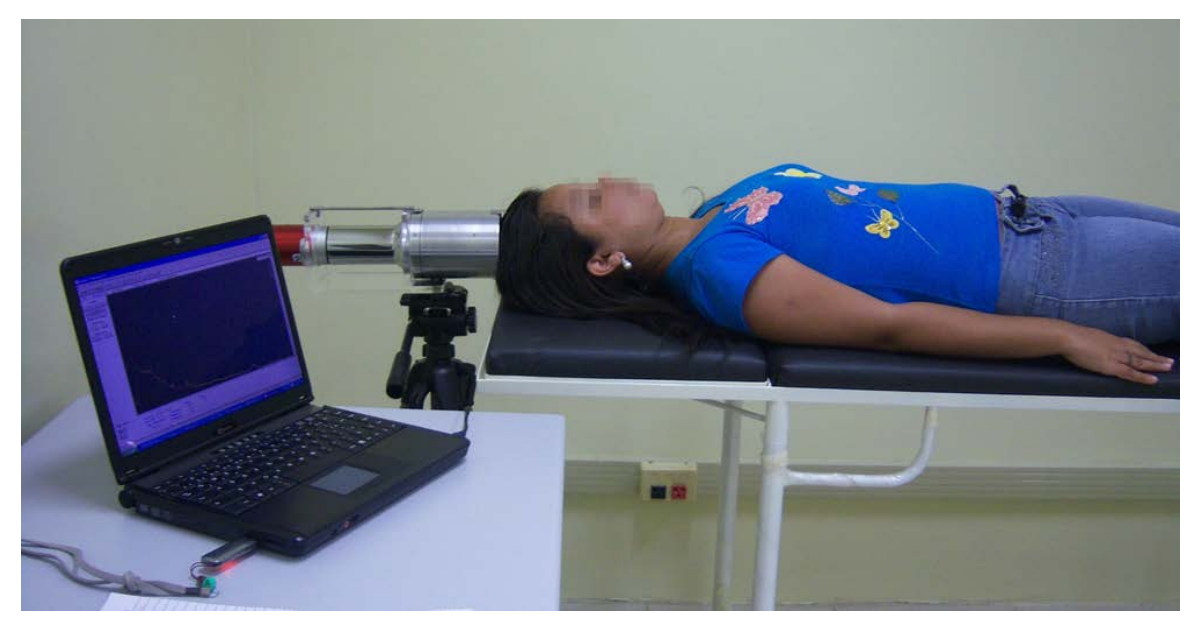

Source: The author

150 measurements were performed in this geometry within 60 days of individual monitoring of internal exposure. In all measurements, seven accidental incorporations were found, resulting in the average incorporated activity of $38.3 \mathrm{MBq}$.

\subsection{Simulations Using Exposure Computational Model}

Based on the average incorporated activity obtained by in vivo bioassay in OEIs at DIPRA/CRCN-NE/CNEN, simulations were performed at the Laboratório de Dosimetria Numérica ( $L D N)$, Instituto Federal de Pernambuco (IFPE). For this purpose, ECM were used to obtain the distribution of the absorbed dose and the value of the effective dose.

In this paper, the ECM were composed by the MC code EGSnrc (Electron Gamma Shower) [7], the voxel phantom in supine position FSUP (Female SUPine) [8] and a modified algorythm simulator of general internal source.

The EGSnrc (expanded and improved version of the EGS4 package) supports Mortran programming language and it is a package for MC simulation of photon-electron coupled 


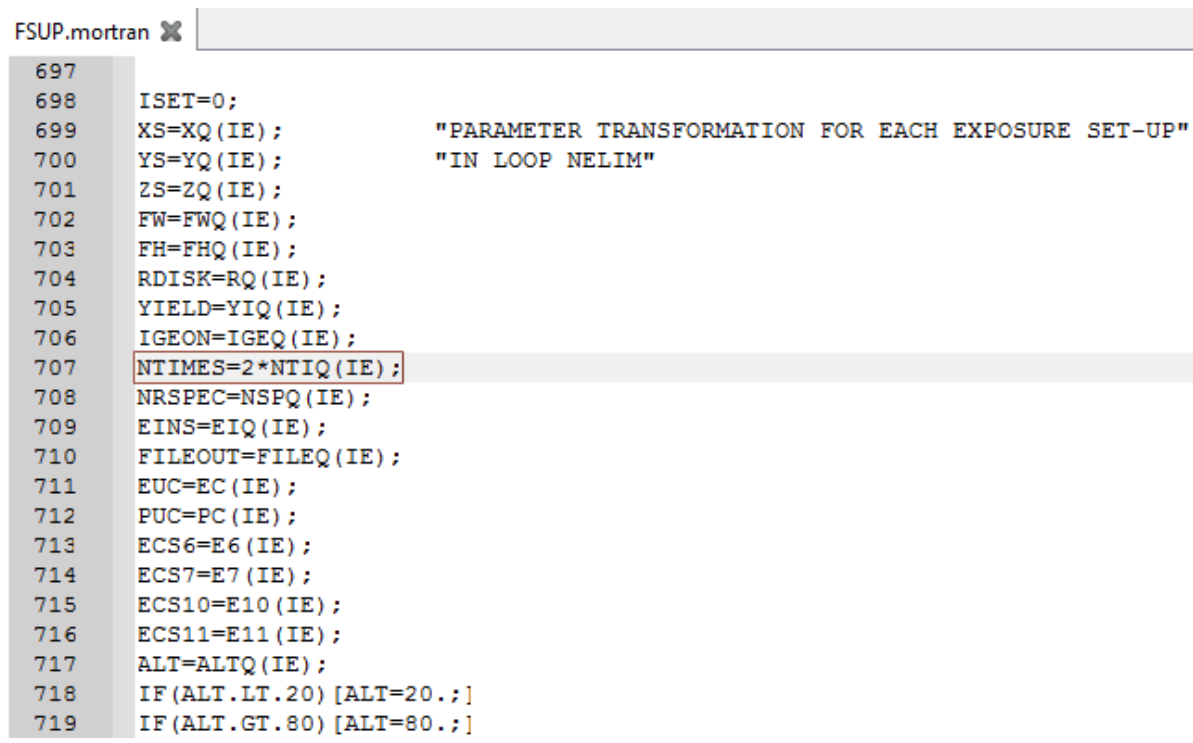

Source: The author

After the changes made in the source algorithm, the EMC were properly organized in specific directory as "C:IHEN_HOUSEIEGS_HOME". To simulate an accidental incorporation case of FDG $-{ }^{18} \mathrm{~F}$ by OEIs, it was necessary to choose the optimal number of histories, which ranged from $1 \times 10^{5}$ to $1 \times 10^{8}$ and to perform other modifications in the standard input file EGSINP, as shown in Figure 5.

Figure 5: Modifications done in the standard file EGSINP. In spotlight, energy and ID values are corresponding to the brain, respectively

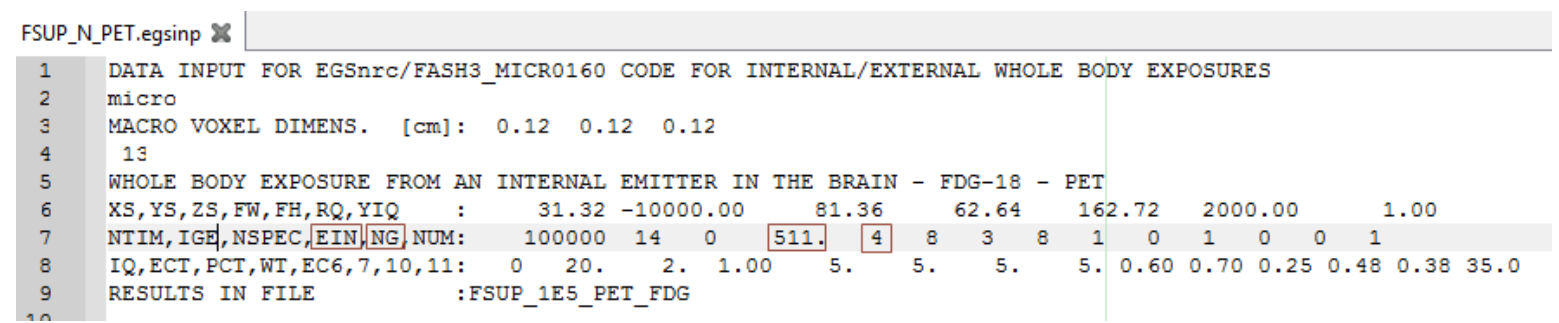

Source: The author 


\section{RESULTS AND DISCUSSION}

The MC code EGSnrc provides output data of dose/accumulated activity in the source organ for a list of organs. From this list, three radiosensitive organs were analyzed (eyes, thyroid and uterus) for choose the ideal number of histories $\left(5 \times 10^{7}\right)$ by means of coefficient of variance. In order to estimate satisfactorily the simulation accuracy, this value could not exceed $5 \%$, as shown in Figure 6.

Figure 6: Coefficient of variance for eyes, thyroid and uterus due to the increase in the number of histories

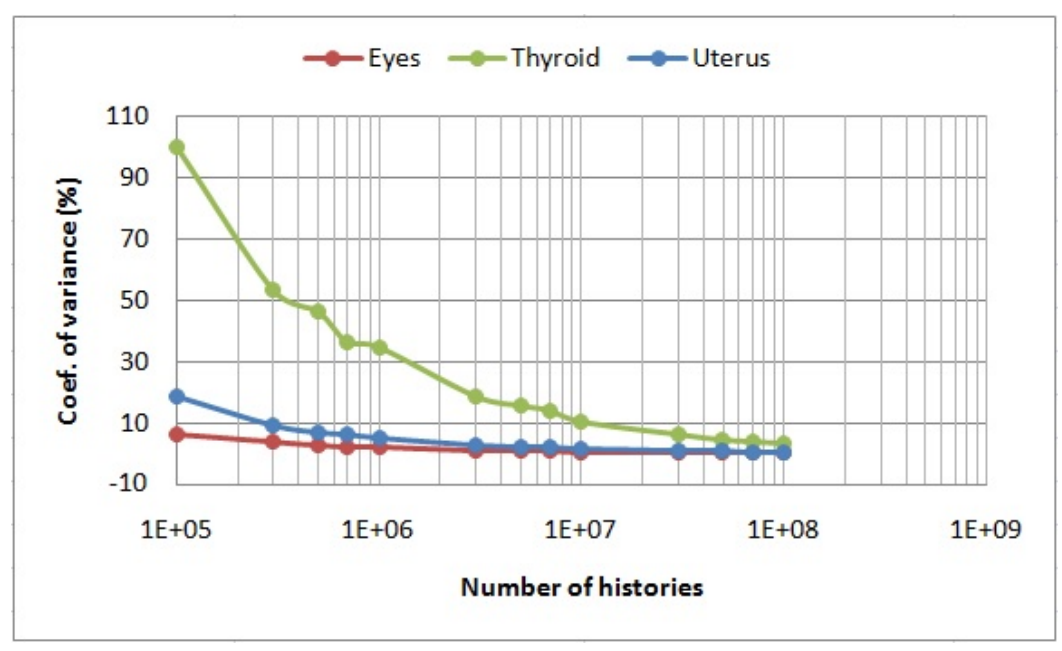

Source: The author

From the selected number of histories, it was possible to obtain results for dosimetric evaluations, which were presented as the ratio of absorbed dose to accumulated activity (mGy/MBq.s). To obtain the absorbed dose distribution in organs, as shown in Table 1, it was necessary to estimate the accumulated activity, which was $29.1 \mathrm{MBq} . \mathrm{s}$, according to Equation 1 [9].

$$
\tilde{A}_{h}=1,443 \cdot A_{h} \cdot f \cdot t_{1 / 2 e f f}
$$


Where:

$\tilde{\mathrm{A}}_{\mathrm{h}}=$ Accumulated activity in organ;

$\mathrm{A}_{\mathrm{h}}=$ Incorporated activity;

$\mathrm{f}=$ Fractional distribution to organ or tissue [10];

$\mathrm{t}_{1 / 2 \mathrm{eff}}=$ Effective half-life.

To estimate the absorbed dose value in organs, only the accumulated activity of radiopharmaceutical in the brain was considered. According to ICRP publication 106 the biological half-life of FDG- ${ }^{18} \mathrm{~F}$ in brain is infinitely long, because it never clears the brain [10]. Then the physical half-life is equal to effective half-life [11].

Table 1: Sample of organs containing values of absorbed dose distribution obtained from accumulated activity and coefficients of variance respectively.

\begin{tabular}{cccc}
\hline Organ & $\begin{array}{c}\text { Absorbed dose/Accumulated activity } \\
\text { (mGy/MBq.s) }\end{array}$ & $\begin{array}{c}\text { Absorbed dose } \\
(\mathrm{mGy})\end{array}$ & $\begin{array}{c}\text { Coefficients of } \\
\text { variance (\%) }\end{array}$ \\
\hline Eyes & $2.5 \times 10^{-6}$ & $7.28 \times 10^{-5}$ & 0.29 \\
Thyroid & $3.1 \times 10^{-7}$ & $9.02 \times 10^{-6}$ & 0.73 \\
Uterus & $1.2 \times 10^{-9}$ & $3.49 \times 10^{-8}$ & 4.76 \\
Brain & $1.0 \times 10^{-5}$ & $2.91 \times 10^{-4}$ & 0.02 \\
Breasts & $4.1 \times 10^{-8}$ & $1.19 \times 10^{-6}$ & 0.60 \\
Stomach Wall & $1.6 \times 10^{-8}$ & $4.66 \times 10^{-7}$ & 1.05 \\
Liver & $2.2 \times 10^{-8}$ & $6.40 \times 10^{-7}$ & 0.33 \\
Lungs & $8.3 \times 10^{-8}$ & $2.42 \times 10^{-6}$ & 0.19 \\
Small Intestine Wall & $3.3 \times 10^{-9}$ & $9.60 \times 10^{-8}$ & 1.11 \\
\hline
\end{tabular}

According to the dosimetric data for the chosen number of histories, the ratio between effective dose and accumulated activity provided by EGSnrc was $2.14 \times 10^{-7} \mathrm{~Sv} / \mathrm{MBq} . \mathrm{s}$. To estimate the effective dose, the estimated value of the accumulated activity was used, resulting in $6.23 \times 10^{-6}$ Sv. The effective dose does not exceed the limits for female occupational exposure. 


\section{CONCLUSIONS}

The estimated absorbed dose distribution and the value of effective dose in this paper did not exceed the limits for occupational exposure. Despite the probability of incorporation of radiopharmaceuticals being small due to safe work conditions, the OEIs can be exposed in unusual conditions, such as accident. Thus, a quantitative analysis of the distribution of energy through the absorbed dose in radiosensitive organs and tissues of OEIs is essential. As perspective a database containing the distribution of accumulated activity to estimate the absorbed and effective dose in OEIs in similar environments is going to be created.

\section{ACKNOWLEDGMENT}

To Laboratório de Dosimetria Numérica (LDN/IFPE) for sharing the location for development of this work, to Departamento de Energia Nuclear (DEN/UFPE), to Centro Regional de Ciências Nucleares do Nordeste (CRCN-NE), to Fundação de Amparo à Ciência e Tecnologia do Estado de Pernambuco (FACEPE) and to Comissão Nacional de Energia Nuclear (CNEN) for the financial support. 


\section{REFERENCES}

1. YORIYAZ, H. "Desenvolvimento de uma metodologia Computacional para cálculos em Dosimetria interna”. 152f. Tese (Doutorado em Ciências) - Universidade de São Paulo. São Paulo, 2000.

2. LACERDA, I. V. B. "Desenvolvimento de metodologias para avaliação da exposição ocupacional interna devido ao radiofármaco 18FDG”. 64f. Dissertação (Mestrado em Tecnologias Energéticas e Nucleares) - Universidade Federal de Pernambuco. Recife, 2013.

3. ICRP - International Commission on Radiological Protection. “General Principles for the Radiation Protection of Workers”. ICRP Publication 75. Oxford, 1997.

4. VIEIRA, J. W. “Construção de um modelo computacional de exposição para cálculos dosimétricos utilizando o código Monte Carlo EGS4 e fantomas de voxels”. 88f. Tese (Doutorado em Tecnologias Energéticas e Nucleares) - Universidade Federal de Pernambuco. Recife, 2004.

5. LEAL NETO, V. et al. "Desenvolvimento Computacional de uma Fonte Radioativa Isotrópica no Solo Utilizando Técnicas Monte Carlo de Amostragem por Rejeição”. Primeiro Congresso Americano do IRPA 2006, XXIV Reunião Anual da SMSR e XVII Congresso Anual da SNM, Acapulco, México, 2006.

6. VIEIRA, J. W. “Uso de técnicas Monte Carlo para determinação de curvas de isodose em Braquiterapia”. Dissertação (Mestrado em Tecnologias Energéticas e Nucleares) Universidade Federal de Pernambuco. Recife, 2001.

7. KAWRAKOW, I., ROGERS, D. W. O. “The EGSnrc code system: Monte Carlo simulation of electron and photon transport”. Technical Report PIRS-701 National Research Council of Canada, Ottawa, Canada, 2003.

8. CASSOLA, V. F. et al. "FASH and MASH: female and male adult human phantoms based on polygon mesh surfaces: I. Development of the anatomy”. Physics in Medicine and Biology, 2010a. 
9. LOEVINGER, R.; BUDINGER, T.F.; WATSON, E.E. in collaboration with MIRD Committee. MIRD PRIMER for absorbed dose calculation, 1991, p. 1-17.

10. ICRP - International Commission on Radiological Protection. Radiation Dose to Patients from Radiopharmaceuticals - Addendum 3 to ICRP Publication 53. ICRP Publication 106. Oxford, 2008.

11. KARESH, S. M. Nuclear Medical Tutorials. Half lives: Physical, biological \& effective. Adapted for the Web by Stephen M. Karesh, PhD \& Marsha Lipps CNMT. Consultants in Nuclear Medicine, Chicago, 2012. Disponível em $<$ http://www.nucmedtutorials.com/dwhalf/index.html>. Acesso em: 27 set 2014 